\title{
Prevalence, etiologies and complications of teeth hypomineralization in pediatrics
}

\author{
Ameera Ibrahim Amer ${ }^{1 *}$, Rana Ali Alsaadi², Malak Abdullah Almajed ${ }^{3}$, \\ Rana Ahmad Alzhrani ${ }^{4}$, Sara Abdullah Asiri ${ }^{4}$, Haifa Mohammed Binthabit ${ }^{4}$, \\ Awadh Owaidh Alazmi ${ }^{5}$, Abdulelah Abdulrahman Alanazi ${ }^{6}$, Ayman Saeed Almutairi ${ }^{7}$, \\ Abrar Zainalabiddin Alharbi ${ }^{8}$, Aseel Khalid Kufiyah'
}

\author{
${ }^{1}$ Department of Pediatrics Dentistry, East Jeddah Hospital, Jeddah, Saudi Arabia \\ ${ }^{2}$ General Dentist, Ministry of Health, Jeddah, Saudi Arabia \\ ${ }^{3}$ General Dentist, Safad Dental Centers, Riyadh, Saudi Arabia \\ ${ }^{4}$ College of Dentistry, King Khalid University, Abha, Saudi Arabia \\ ${ }^{5}$ General Dentist, Ministry of Health, Qassim Ayoun Aljawa, Saudi Arabia \\ ${ }^{6}$ College of Dentistry, Majmaah University, Riyadh, Saudi Arabia \\ ${ }^{7}$ General Dentist, Buraydah Central Hospital, Qassim-Buraydah, Saudi Arabia \\ ${ }^{8}$ General Dentist, Ministry of Health, Yanbu, Saudi Arabia \\ ${ }^{9}$ College of Dentistry, Umm Al-Qura University, Mecca, Saudi Arabia
}

Received: 12 May 2021

Accepted: 28 May 2021

\section{*Correspondence:}

Dr. Ameera Ibrahim Amer,

E-mail: ameera-dent@hotmail.com

Copyright: () the author(s), publisher and licensee Medip Academy. This is an open-access article distributed under the terms of the Creative Commons Attribution Non-Commercial License, which permits unrestricted non-commercial use, distribution, and reproduction in any medium, provided the original work is properly cited.

\begin{abstract}
Dental hypomineralization represents a major problem in childhood health that can cause serious problems and may even affect the permanent dentition. In previous literature review, the term molar incisor hypomineralization $(\mathrm{MIH})$ has been frequently reported among different studies. However, the clinical problems and complications of the condition are not commonly described among studies in the literature, which adds a value to this current study. The present study was a literature review that aimed to discuss the problems of hypomineralization in baby teeth and the reported common problems according to recent studies in the literature. Tooth loss, anesthetic problems within the anterior teeth, hypersensitivity and the presence of underlying inflammation are potential complications that might affect these patients. Moreover, it was also previously reported that the subsurfaces of the affected enamels are usually porous and soft. On other hand, the surfaces of the intact enamels are usually hypermineralized, hard and smooth, owing to the subsequent post-eruptive maturation. Identification of the underlying etiology and risk factors is important for the proper management of these cases. A systemic origin of the disorder was strongly suggested while other environmental and genetic factors had been suggested. Moreover, establishing a proper diagnosis can be hard due to the presence of some similar disorders. Therefore, a differential diagnosis should be established as it is discussed in this literature.
\end{abstract}

Keywords: Hypomineralization, Dentistry, Complications, Pediatrics, MIH

\section{INTRODUCTION}

Teeth hypomineralization represents a major problem in childhood health that can cause serious problems and may even affect the permanent dentition. In previous literature reviews, the term MIH has been frequently reported among different studies. The term was first reported by Weerheij et al who defined the disorder as the presence of hypomineralization of the enamel of $1-4$ the first permanent molars that may be or may not be associated 
with incisors and is usually owing to a systemic disorder and the affected parts present with qualitative demarcated defects. ${ }^{1}$ Before this present study, authors and clinicians tended to name the phenomenon as internal enamel hypoplasia, opacities of non-fluoride enamels, enamel non-endemic mottling, cheese molars and idiopathic enamel opacities. $^{2,3}$ On the other hand, hypoplasia has been previously found to affect only the external surface of the tooth that is usually attributable to an external defect that usually impacts the thinnest region of the tooth. The clinical presentation of hypoplasia might be deep or shallow fossae with total or partial absence of the enamel and with vertical or horizontal grooves.

In 2003, another description of MIH was furtherly found in the literature as Weerheij et al reported that MIH can be observed as a developmental qualitative defect of the enamel of the affected tooth that is attributable to hypomineralization and reduced organic components of the enamel, which will subsequently result in significant discoloration and fracture events. ${ }^{4}$ Although the early studies have reported that hypomineralization frequently affects the incisors and first primary molars only. Moreover recent studies in the literature reported that different teeth can be affected including the permanent and primary ones. ${ }^{5}$ When $\mathrm{MIH}$ is observed, it has been reported that dental caries are significantly present and most cases rapidly progress following eruption leading to significant adverse events that may also complicate the management of these teeth. ${ }^{2}$

Although the current prevalence of the condition makes it a common one that is usually observed daily in practice within the dental clinics. ${ }^{6,7}$ It has been reported in recent investigations that significant difficulties and hazards have been reported by dentists when approaching the diagnosis and management of these conditions. ${ }^{6,8,9}$ Moreover, the clinical problems and complications of the condition are not commonly described among studies in the literature, which adds value to this current study. The present study was a literature review that aimed to discuss the problems of hypomineralization in baby teeth and the reported common problems according to recent studies in the literature.

\section{METHODS}

A systematic search was conducted to identify relevant studies in the databases like PubMed, Medline, Web of Science, Embase, Google Scholar and Scopus. The following search terms were used (prevalenec) and (etiology or causes) and (hypomineralization) and (pediatric or pediatrics or children). The reference lists were manually searched to identify additional relevant studies meeting inclusion criteria. We included any study that reports iatrogenic tooth discoloration by obturating material. No restrictions were applied.

\section{DISCUSSION}

\section{Complications and clinical presentation}

According to the various studies in the literature and case reports, patients with teeth hypomineralization usually present with the following symptoms, including rapid progression of caries, hypersensitivity, difficult anesthesia, a potential breakdown of the enamels posteruption and the affected tooth may be yellow-brown or whitish-creamy in color demarcated large significant opacities. It is now well-known that the lesions that are caused by the MIH are usually larger with demarcated opacities with variable translucency of the affected enamels. It has also been reported that the lesion or opacity usually involves only one-third of the cuspal or incisal surface of the crowns of the affected teeth and is usually limited to it. Moreover, it was also previously reported that the subsurfaces of the affected enamels are usually porous and soft. On the other hand, the surfaces of the intact enamels are usually hypermineralized, hard and smooth, owing to the subsequent post-eruptive maturation. ${ }^{10,11}$ Moreover, it has been reported that the first permanent molars with MIH might acquire more sensitivity and be hypersensitive, which usually requires the administration of more anesthesia, and it can still be difficult to achieve. Previous investigations have also demonstrated that some patients might experience hypersensitivity as a result of the porosity of the enamels that might lead to the development of certain degrees of underlying subclinical inflammation, which might be attributable to the sequence of these events. ${ }^{10,11}$ These suggestions were indicated by more recent studies. For instance, a previous comparative investigation by Rodd et al reported that the changes that were observed among their included population with MIH showed that significant pathological observations were noticed among their noncarious than the seemingly sound population with hypo mineralized first primary molars, which was also attributable mainly to an underlying inflammatory reaction. ${ }^{12}$ The significant impact of the porous enamel can also be observed during the process of caries progression which is usually bad owing to this pathology when it affects the first primary molars that suffer from hypomineralization. Finally, previous studies have also demonstrated the affected patients and children might be advised against brushing their teeth as a result of the potential presence of sensitivity, which might also complicate the case and worsen the presence of caries. ${ }^{10,13}$ Tooth loss and anesthetic problems within the anterior teeth have also been reported as other two potential complications. As a result of potential enamel roughness, delayed eruption and associated difficulties might also be present. As a result of the failure to induce anesthesia, it has also been reported that surgical traumatic complications might constitute a potential complication due to the potential presence of pain resulting in problems with the behavioral management of these patients. ${ }^{14}$ 


\section{Etiology}

The exact etiology of pediatric teeth hypomineralization is still not adequately understood. ${ }^{8,15}$ However, it has been previously suggested by some studies that the process of hypomineralization might be attributable to a systemic nature with the distribution of the amelogenesis process, which probably occur early during the late secretory phase or somewhen later during the maturation phase.,16 Moreover, studies have also reported the involvement of many factors which might also be considered risk factors that can in the early identification and prevention of the disease. For instance, some authors suggested that environmental factors might play significant roles when exposure occurs during the first years of life or even during pregnancy within the last months. ${ }^{15,17}$ Besides, as previously discussed, the presence of certain underlying systemic diseases, whether acute or chronic, has also been previously reported as significant etiologies. Moreover, it has also been suggested that the frequency and distribution of the number of the affected teeth and the potential lesions have also been previously linked with the time and period of the occurrence and exposure to the potential etiologies and risk factors. For instance, it has been reported that whether the systemic disease occurred in the post-natal, prenatal or perinatal periods was significantly associated with the frequency of lesions in a progressive manner. ${ }^{17}$ There are many factors that might contribute to the development of tooth hypomineralization such as dioxins, perinatal complications, respiratory tract infections, oxygen starvation, phosphate and calcium metabolic diseases, low birth weight, frequent illnesses during childhood, prolonged breastfeeding and overuse of antibiotics., ${ }^{2}$-26 Additionally, previous studies have demonstrated that genetic and family disorders might also constitute a significant factor in addition to the presence of systemic disorders in which it might contribute to the development of hypomineralization in children. ${ }^{27,28}$

\section{Prevalence}

The prevalence of MIH has been reported among many epidemiological studies in the literature, which showed hugely variable rates among the different populations. The reported cumulative prevalence rate for the global studies has been previously estimated to be ranging from $2.8 \%$ to $40.2 \% .{ }^{29}$ It has also been previously stated that such variations are probably due to the potential underestimation of the real prevalence rates. The reduced tools and techniques that are used to diagnose and record the prevalence of hypomineralization and $\mathrm{MIH} .{ }^{29-31}$ According to the previous criteria by the European academy of paediatric dentistry for evaluation of hypomineralization, a previous investigation by Ghanim et al reported that they have developed a scoring system to standardize the evaluation and diagnosis of hypomineralization. ${ }^{32}$ Another investigation was also recently published to furtherly facilitate the process of standardization and application of the system by future epidemiological investigations aiming at reporting the prevalence rates of hypomineralization. ${ }^{29}$ It has been suggested by Elfrink et al that for the proper estimation of the prevalence rates, at least 300 individuals should be included within such studies. ${ }^{30}$ Finally, it has been recently estimated that $\mathrm{MIH}$ and hypomineralization usually affect one per six children globally. ${ }^{7}$

\section{Differential diagnosis}

Many problems should be considered when evaluating hypomineralization in children to establish a proper diagnosis and adequate management. Previous studies have demonstrated the potential similarities between MIH and other dental disorders that are discussed in the following lines. ${ }^{29,33}$ Among the reported condition in these studies, fluorosis is a common condition that should be considered which might result from excessive intake of fluoride during the development of enamels. In the clinical setting, it should be noted that patients with fluorosis might present with confluent or patchy opacities, with ill-defined boundaries and can also be linear and diffuse. The severity of the condition is variable among patients as in some cases major disfiguration of the affected tooth might be observed with the absence of demarcations and complete loss of the outer part of the enamel, while in milder cases the condition is usually observed as barely observable stations within the affected enamels. Moreover, it has also been noticed that MIH usually affects teeth in an asymmetrical pattern, which is unlike fluorosis which is usually bilateral and symmetric. Finally, another difference is that caries is common complications in patients with $\mathrm{MIH}$, while patients with fluorosis are not usually associated with such complications are cariesresistant.

Decreased thickness of the enamel or enamel hypoplasia is another differential diagnosis with teeth hypomineralization. A pre-eruptive lack of the affected part is indicated as the condition is usually associated with smooth and regular surfaces, owing to hypoplasia. The condition is different in cases with MIH, as it has been previously reported to be associated with post-eruptive shearing of the affected enamels leading to the development of irregular and sharp borders. Amelogenesis imperfecta has also been previously reported among studies as genetic conditions that affect the enamels, which are usually observed as hypomature, hypoplastic or hypomineralized. To diagnose this condition, it has been reported that family history can be associated and all the primary and permanent teeth are usually impacted. Having a previous history of significant trauma to the primary predecessor tooth might also be a cause of traumatic hypomineralization which should be considered when evaluation dental tooth hypomineralization. Within the underlying tooth germ, it has been expressed that the presence of periapical infections can disturb the growth and mineralization of the affected teeth. The trauma usually affects one tooth and is more 
logical to be asymmetric. Finally, patients might present with different observations due to the difference in localization, shape, outline and color. White spot lesions might also be misdiagnosed with hypomineralization; however, they should be differentiated as they are known as the earliest clinical observations for dental caries. They can be easily diagnosed when comparing them to the adjacent enamels, as they have been reported to be matt, chalkier or probably more opaque. The cervical margins of the teeth are the most probable common areas for these events as they are usually associated with plaque stagnation, which should differentiate the condition from MIH and hypomineralization.

\section{CONCLUSION}

In the present study, it discussed the potential common complications and clinical presentations that patients with tooth hypomineralization usually suffer during childhood. According to the evidence obtained from several studies in the current literature, tooth loss, anesthetic problems within the anterior teeth, hypersensitivity and the presence of underlying inflammation are potential complications that might affect these patients. Additionally, identification of the underlying etiology and risk factors is important for the proper management of these cases. Moreover, establishing a proper diagnosis can be hard due to the presence of some similar disorders. Therefore, a differential diagnosis should be established as well as future studies are needed as it is discussed in this literature.

Funding: No funding sources Conflict of interest: None declared

Ethical approval: Not required

\section{REFERENCES}

1. Weerheijm KL, Jälevik B, Alaluusua S. Molarincisor hypomineralisation. Caries Res. 2001;35(5):390-1.

2. Weerheijm KL. Molar incisor hypomineralization (MIH): clinical presentation, aetiology and management. Dent Update. 2004;31(1):9-12.

3. Weerheijm K, Groen H, Beentjes V, Poorterman J. Prevalence in 11-year-old Dutch children of cheese molars. Eur J Paediatr Dent. 2000;3(2):131-3.

4. Weerheijm KL, Duggal M, Mejàre I, Papagiannoulis L, Koch G, Martens LC, et al. Judgement criteria for molar incisor hypomineralisation (MIH) in epidemiologic studies: a summary of the European meeting on MIH held in Athens, 2003. Eur J Paediatr Dent. 2003;4(3):110-3.

5. Steffen R, Waes VH. Therapy of molar incisor hypomineralisation under difficult circumstances. A concept for therapy. Quintessenz. 2011;62:1613-23.

6. Kalkani M, Balmer RC, Homer RM, Day PF, Duggal MS. Molar incisor hypomineralisation: experience and perceived challenges among dentists specialising in paediatric dentistry and a group of general dental practitioners in the UK. Eur Arch Paediatr Dent. 2016;17(2):81-8.

7. Hubbard MJ. Molar hypomineralization: What is the US experience? J Am Dent Assoc. 2018;149(5):32930.

8. Silva MJ, Alhowaish L, Ghanim A, Manton DJ. Knowledge and attitudes regarding molar incisor hypomineralisation amongst Saudi Arabian dental practitioners and dental students. Eur Arch Paediatr Dent. 2016;17(4):215-22.

9. Hussein AS, Ghanim AM, Abu-Hassan MI, Manton DJ. Knowledge, management and perceived barriers to treatment of molar-incisor hypomineralisation in general dental practitioners and dental nurses in Malaysia. Eur Arch Paediatr Dent. 2014;15(5):3017.

10. Weerheijm KL. Molar incisor hypomineralisation (MIH). Eur J Paediatr Dent. 2003;4(3):114-20.

11. Jälevik B. Enamel hypomineralization in permanent first molars. A clinical, histo-morphological and biochemical study. Swed Dent J Suppl. 2001;(149):1-86.

12. Rodd HD, Boissonade FM, Day PF. Pulpal status of hypomineralized permanent molars. Pediatr Dent. 2007;29(6):514-20.

13. Beentjes V, Weerheijm K, Groen H. A matchcontrol study into the aetiology of hypomineralised first permanent molars. Eur J Paediatr Dent. 2000;1:123.

14. Almuallem Z, Busuttil-Naudi A. Molar incisor hypomineralisation (MIH)-an overview. Brit Dent J. 2018;225(7):601-9.

15. Crombie F, Manton D, Kilpatrick N. Aetiology of molar-incisor hypomineralization: a critical review. Int J Paediatr Dent. 2009;19(2):73-83.

16. Alam M, Raza SJ, Sherali AR, Akhtar AS. Neonatal complications in infants born to diabetic mothers. J Coll Physicians Surg Pak. 2006;16(3):212-5.

17. Lygidakis NA, Dimou G, Marinou D. Molarincisor-hypomineralisation $(\mathrm{MIH})$. A retrospective clinical study in Greek children. II. Possible medical aetiological factors. Eur Arch Paediatr Dent. 2008;9(4):207-17.

18. Kreshover SJ, Clough OW. Prenatal influences on tooth development. II. Artificially induced fever in rats. J Dent Res. 1953;32(4):565-77.

19. Norwitz ER, Robinson JN, Challis JR. The control of labor. N Engl J Med. 1999;341(9):660-6.

20. Tsang RC, Donovan EF, Steichen JJ. Calcium physiology and pathology in the neonate. Pediatr Clinic North Am. 1976;23(4):611-26.

21. Rösli A, Fanconi A. Neonatal hypocalcaemia. "Early type" in low birth weight newborns. Helvetica Paediatrica Acta. 1973;28(5):443-57.

22. Behrman RE, Vaughan VC. In: Nelson WE, eds. Nelson textbook of pediatrics. 12th ed. India: WB Saunders company; 1983.

23. Beentjes VE, Weerheijm KL, Groen HJ. Factors involved in the aetiology of molar-incisor 
hypomineralisation (MIH). Eur J Paediatr Dent. 2002;3(1):9-13.

24. Jälevik B, Odelius H, Dietz W, Norén J. Secondary ion mass spectrometry and X-ray microanalysis of hypomineralized enamel in human permanent first molars. Archiv Oral Biol. 2001;46(3):239-47.

25. Alaluusua S, Calderara P, Gerthoux PM, Lukinmaa $\mathrm{P}$, Kovero O, Needham L, et al. Developmental dental aberrations after the dioxin accident in Seveso. Environ Health Perspect. 2004;112(13):1313-8.

26. Jan J, Sovcikova E, Kocan A, Wsolova L, Trnovec T. Developmental dental defects in children exposed to PCBs in eastern Slovakia. Chemosphere. 2007;67(9):S350-4.

27. Teixeira R, Andrade NS, Queiroz LCC, Mendes FM, Moura MS, Moura LDFADD, et al. Exploring the association between genetic and environmental factors and molar incisor hypomineralization: evidence from a twin study. Int J Paediatr Dent. 2018;28(2):198-206.

28. Fuenfer MM, Pyrtek LJ, Krisiunas L, Schweizer RT. The value of cryo-preservation of parathyroid tissue. Connecticut Med. 1986;50(9):610-1.

29. Ghanim A, Silva MJ, Elfrink MEC, Lygidakis NA, Mariño RJ, Weerheijm KL, et al. Molar incisor hypomineralisation (MIH) training manual for clinical field surveys and practice. Eur Arch Paediatr Dent. 2017;18(4):225-42.

30. Elfrink ME, Ghanim A, Manton DJ, Weerheijm KL. Standardised studies on molar incisor hypomineralisation (MIH) and hypomineralised second primary molars (HSPM): a need. Eur Arch Paediatr Dent. 2015;16(3):247-55.

31. Jälevik B. Prevalence and diagnosis of molarincisor- hypomineralisation (MIH): a systematic review. Eur Arch Paediatr Dent. 2010;11(2):59-64.

32. Ghanim A, Elfrink M, Weerheijm K, Mariño R, Manton D. A practical method for use in epidemiological studies on enamel hypomineralisation. Eur Arch Paediatr Dent. 2015;16(3):235-46.

33. Denis M, Atlan A, Vennat E, Tirlet G, Attal JP. White defects on enamel: diagnosis and anatomopathology: two essential factors for proper treatment (part 1). Int Orthodont. 2013;11(2):13965.

Cite this article as: Amer AI, Alsaadi RA, Almajed MA, Alzhrani RA, Asiri SA, Binthabit HM, et al. Prevalence, etiologies and complications of teeth hypomineralization in pediatrics. Int $\mathrm{J}$ Community Med Public Health 2021;8:3698-702. 